\title{
Disponibilidade hídrica de dois solos e diferentes idades de corte no comportamento agronômico da Jureminha ${ }^{1}$
}

\author{
Water availability of two soil-types and at different cropping ages on the agronomic \\ performance of Jureminha
}

\author{
Manoel Alexandre Diniz Neto ${ }^{2 *}$, Rossana Carla Montenegro de Vasconcelos ${ }^{3}$, Lourival Ferreira Cavalcante ${ }^{4}$, \\ Edgard Cavalcanti Pimenta Filho ${ }^{5}$ e Ivandro de França da $\mathrm{Silva}^{4}$
}

\begin{abstract}
RESUMO - O trabalho foi desenvolvido para avaliar os efeitos de dois solos submetidos a níveis de disponibilidade de água e idade de corte nos componentes de crescimento vegetativo e composição bromatológica em plantas de jureminha (Desmanthus virgatus L. Willd.). Os tratamentos foram distribuídos em arranjo fatorial $2 \times 4$ em delineamento de blocos casualizados com doze repetições, com os fatores: dois solos, sendo um da região úmida do município de Alagoinha e outro da região semiárida do município de São João do Cariri, ambos no Estado da Paraíba; quatro níveis de disponibilidade de água $(40 ; 60 ; 80$ e 100\% de água disponível) e quatro idades de corte $(60 ; 90 ; 120$ e 150 dias após a emergência das plântulas) conduzidos em casa-de-vegetação do CCA/UFPB, Areia-PB. O aumento da água disponível no solo estimula o crescimento das plantas, mas inibe a produção de proteína bruta da jureminha. As plantas cresceram mais e produziram menos proteína bruta no solo de São João do Cariri em relação ao solo de Alagoinha.
\end{abstract}

Palavras-chave: Desmanthus virgatus L. Plantas. Água.

\begin{abstract}
The study was developed to evaluate the effects of two soil-types under different levels of water availability and cropping ages on the components of vegetative growth and chemical composition of jureminha plants (Desmanthusvirgatus L. Willd.). The treatments were distributed in a $2 \times 4$ factorial in a completely randomized block design with twelve replications of the factors: two soil types, one being from the humid region of the town of Alagoinha, and other from the semi-arid region of the town of São João do Cariri, both in the State of Paraíba; four levels of water availability $(40,60,80$ and $100 \%$ of the available water) and four cropping ages $(60 ; 990 ; 120$ and 150 days after the emergence of seedlings), the study being carried out in a greenhouse at CCA / UFPB, in Areia, Paraíba. An increase in the water available in the soil stimulates plant growth but inhibits gross protein production in jureminha. Plants grew more, and produced less protein in the soil from São João do Cariri in relation to that from Alagoinha.
\end{abstract}

Key words: Desmanthus virgatus L. Plants. Water.

\footnotetext{
* Autor para correspondência

${ }^{1}$ Recebido para publicação em 24/09/2010; aprovado em 22/06/2012

Parte da Dissertação de Mestrado em Manejo de Solo e Água do segundo autor

${ }^{2}$ Pesquisador-Bolsista PNPD/PPGCS/CCA/CAPES, Universidade Federal da Paraíba, Areia-PB, Brasil, diniznetto@ gmail.com

${ }^{3}$ Programa de Pós-Graduação em Agronomia/CCA, Universidade Federal da Paraíba, Areia-PB, Brasil, rossanacmv@ hotmail.com

${ }^{4}$ Departamento de Solos e Engenharia Rural/CCA, Universidade Federal da Paraíba, Areia-PB, Brasil, lofeca@cca.ufpb.br, edgard@cca.ufpb.br

${ }_{5}^{5}$ Departamento de Zootecnia/CCA, Universidade Federal da Paraíba, Areia-PB, Brasil, ivandro@cca.ufpb.br
} 


\section{INTRODUÇÃO}

Expresso pela sua extensão continental, pela diversidade e endemismo das espécies biológicas e seu patrimônio genético, bem como pela variedade ecossistêmica dos biomas, o patrimônio natural brasileiro apresenta grande relevância mundial (ASSUNÇÃO; FELFILI, 2004). Entre as famílias mais representativas da flora no mundo, segundo Fontenele, Aragão e Rangel (2007), a Leguminosae (Fabaceae) é uma das mais expressivas pela fixação de nitrogênio no solo e seu repasse ao agroecossistema, presença em vários sistemas agrícolas pela sua agressividade na dispersão de sementes, além de possuir relevante potencial forrageiro, o que representa expressiva importância para regiões onde as chuvas são irregulares como na região semiárida.

Os fatores edafoclimáticos do semiárido favorecem o desenvolvimento de uma vegetação adaptada às suas adversidades, formada, em sua maioria, por plantas xerófilas e caducifólias, originando um tipo de formação florestal denominado de Caatinga (LIMA, 1996). A Caatinga, por ser de natureza caducifólia, não fornece, nas épocas secas do ano, alimentos que possam suprir, quantitativa e qualitativamente, as necessidades dos animais (DANTAS NETO et al., 2000).

O cultivo e o uso planejado e diversificado de opções forrageiras, nativas e/ou introduzidas, anuais e/ ou perenes, para produção de feno ou silagem, somadas a outras opções como resíduos agroindustriais e outros ingredientes de potencial regional, segundo Lima, Araújo e Maciel (2009) podem aumentar a chance de sucesso dos sistemas de produção pecuária do semiárido nordestino e as opções, acrescentando respectivos autores, sugerem a existência de alternativas viáveis para a construção de suportes alimentares que possibilitem produção sustentável familiar do semiárido nordestino. Entretanto, se faz necessário um bom planejamento para se obter maior eficiência no uso de pequenas áreas, com utilização de espécies forrageiras adaptadas às diferentes condições edafoclimáticas da região.

Dentre as espécies nativas que têm despertado interesse de vários pesquisadores, a jureminha (Desmanthus virgatus (L) Willd) Leguminosa e, Mimosoidae apresentase como uma forrageira, perene de porte sublenhoso $(0,3$ a 1,5 m), rica em proteína (até $18 \%$ no feno), que produz grande quantidade de sementes e revela-se promissora tanto para ser utilizada na agricultura como na pecuária. Porém, sua utilização ainda ocorre de forma incipiente na pecuária em pastagens naturais, cultivadas, consorciadas ou em bancos de proteínas, como na agricultura para uso na adubação verde e como planta de cobertura (ALCÂNTARA; BUFARAH, 1999; FONTENELE; ARAGÃO; RANGEL, 2007).
Usada principalmente como forragem e pasto, segundo Figueiredo et al. (2000), a jureminha possui alta palatabilidade, elevada taxa de crescimento e resistência ao corte e pastejo, podendo ser feitos quatro cortes por ano, além de dispor de alta taxa de produção de sementes. É uma planta tolerante às adversidades climáticas das regiões semiáridas adaptando-se aos locais com índices pluviométricos entre 250-1.500 mm e altitude de até $1.250 \mathrm{~m}$.

Tida como uma das principais leguminosas estudadas e utilizadas na alimentação animal na região semiárida do Nordeste brasileiro, seguida da maniçoba (Manihot pseudoglaziovii Paz \& Hoffman) e do feijão bravo (Capparis flexuosa), a jureminha apresenta alta capacidade de adaptar-se às condições climáticas adversas em determinadas épocas do ano, caracterizadas pela baixa disponibilidade de água no solo (COSTA et al., 2007).

Na Paraíba, em diversas microrregiões, a jureminha ocorre naturalmente e é utilizada como forragem para os mais diversos rebanhos. Considerando, porém, as possibilidades de exploração dessa planta segundo Guedes et al. (2005), estudos foram realizados com o objetivo de avaliar os efeitos de diferentes solos submetidos à irrigação, sobre a germinação, crescimento vegetativo, composição bromatológica e fenação (FIGUEIREDO; PIMENTA FILHO; GUIM, 1999); e silagem (SILVA et al., 2004), demonstrando a importância dessa espécie para essa região. Nesse sentido, o objetivo com o trabalho foi avaliar o comportamento da jureminha em diferentes níveis de água no solo e idades de corte sobre as principais características de crescimento e biomassa dessa espécie como suporte para alimentação animal no semiárido paraibano.

\section{MATERIAL E MÉTODOS}

O experimento foi conduzido em casa de vegetação do Centro de Ciências Agrárias da Universidade Federal da Paraíba, Campus de Areia-PB, no período de agosto de 2005 a março de 2006. Foram utilizados dois solos com suas classificações realizadas segundo Empresa Brasileira de Pesquisa Agropecuária (2006) como Nitossolo Háplico eutrófico, descrito em área pertencente à Estação Experimental da EMEPA, município de Alagoinha, e Vertissolo Háplico carbonático descrito em área pertencente à Estação Experimental de São João do Cariri (CCA/UFPB), sendo as amostras coletadas a profundidade de $30 \mathrm{~cm}$ em ambas as estações experimentais, todas localizadas no Estado da Paraíba. As amostras de solo foram preparadas e analisadas nos Laboratórios de Física e de Química e Fertilidade do Solo, ambos pertencentes ao Centro de Ciências Agrárias da UFPB, seguindo metodologia recomendada pela Empresa Brasileira de Pesquisa Agropecuaria (1997). 
O delineamento experimental empregado foi o de blocos casualizados com os tratamentos em esquema fatorial 2 x 4 com amostras subdivididas no tempo com dois solos (Nitossolo Háplico eutrófico e Vertissolo Háplico carbonático), quatro níveis de água (40;60;80 e $100 \%$ de água disponível) e quatro idades de cortes das plantas $(60 ; 90 ; 120$ e 150 dias após a emergência das plântulas), com doze repetições totalizando 384 unidades experimentais. Os cortes foram realizados aos 60; 90; 120 e 150 dias após a emergência das plântulas, de modo que 96 amostras eram coletadas e avaliadas a cada 30 dias.

O cálculo de água disponível para cada solo foi feito pela diferença dos valores percentuais de umidade volumétrica obtidos em amostras previamente saturadas em placas de Richards (1965), e submetidas às tensões de -0,03 MPa e -1,5 MPa até o equilíbrio correspondente à capacidade de campo e de murchamento permanente de cada solo. Esse valor corresponde aos $100 \%$ do valor da água disponível de cada solo. Em seguida quantificaram-se os volumes referentes a 80; 60 e $40 \%$ da água disponível para cada solo (Tabela 1).

A semeadura constou de 10 sementes por unidade experimental deixando apenas uma plântula após o desbaste que ocorreu na primeira semana da semeadura. As unidades experimentais foram representadas por vasos plásticos com capacidade para 10 litros, contendo $8,0 \mathrm{~kg}$ de solo seco ao ar, e durante a fase de germinação e estabelecimento das plântulas, a irrigação foi feita diariamente pelo processo de pesagem de modo a manter os tratamentos com umidade equivalente a $100 \%$ de água disponível durante trinta dias.

A partir do trigésimo dia, as irrigações foram feitas a cada 48 horas, fornecendo-se os volumes com base na pesagem dos vasos para manutenção da água disponível em 40; 60; 80 e 100\% em cada solo. Para tal operação foi calculado o volume de água disponível em peso e a quantidade do material de cada solo nos seus respectivos percentuais, os quais foram feitos repondo a cada solo o volume de água evapotranspirada, de modo a manter o valor padrão inicial (Tabela 1).

As determinações físicas do solo constaram da análise granulométrica, obtida pelo método do hidrômetro, conforme Bouyoucos (1951) modificada por Day (1965) e da umidade em peso correspondente aos valores da capacidade de campo e ponto de murcha permanente em amostras com estrutura deformada e previamente saturadas com água e submetidas às tensões de $-0,01 ;-0,033$ e $-1,5 \mathrm{MPa}$ em câmara de pressão de Richards (1965) e as determinações químicas realizadas empregando a metodologia descrita por Tedesco, Volkweiss e Bohner (1985) conforme pode-se observar na Tabela 2.

Após 60; 90; 120 e 150 dias da emergência das plântulas, foram medidos o crescimento em altura e diâmetro caulinar, contados o número de folhas e de folíolos. Em seguida, foram selecionadas ao acaso, três repetições (amostras destrutivas) de cada tratamento para avaliação da massa seca da parte aérea e das raízes. Nas últimas três repetições de cada tratamento, aos 150 dias, além das respectivas variáveis avaliadas aos 60; 90 e 120 dias, foram obtidos os valores de proteína bruta na matéria seca da parte aérea das plantas pelo método de Kjeldahl descrito por Silva (1990) e da umidade em cada tipo de solo por Richards (1965).

$\mathrm{Na}$ semana anterior a cada corte, o solo era irrigado com solução nutritiva contendo $2,33 \mathrm{~g}$ de sulfato de amônio ( $20 \%$ de N); 5,60 g de superfosfato triplo $\left(40 \%\right.$ de $\left.\mathrm{P}_{2} \mathrm{O}_{5}\right)$ e $0,90 \mathrm{~g}$ de cloreto de potássio (60\% de $\left.\mathrm{K}_{2} \mathrm{O}\right)$, diluídos em dez litros de água e fornecidos os volumes em 100; 80; 60 e $40 \mathrm{ml}$ nos tratamentos correspondentes a $100 ; 80 ; 60$ e $40 \%$ de água disponível de cada solo, aos 30; 60; 90 e

Tabela 1 - Volumes de água referentes aos percentuais de disponibilidade às plantas em cada solo. Areia-PB, 2006

\begin{tabular}{|c|c|c|}
\hline Tipos de solo & Água Disponível (\%) & Volume $\left(\mathrm{cm}^{3}\right)$ \\
\hline \multirow{4}{*}{$\begin{array}{l}\text { Nitossolo Háplico eutrófico } \\
\text { Alagoinha-PB }\end{array}$} & 40 & 182 \\
\hline & 60 & 274 \\
\hline & 80 & 365 \\
\hline & 100 & 456 \\
\hline \multirow{4}{*}{$\begin{array}{l}\text { Vertissolo Háplico carbonático } \\
\text { São João do Cariri-PB }\end{array}$} & 40 & 208 \\
\hline & 60 & 321 \\
\hline & 80 & 416 \\
\hline & 100 & 520 \\
\hline
\end{tabular}


Tabela 2 - Atributos físicos dos solos coletados nos municípios paraibanos de Alagoinha e São João do Cariri, 2006

\begin{tabular}{|c|c|c|c|c|c|c|c|c|c|}
\hline \multirow{3}{*}{ Locais } & \multicolumn{9}{|c|}{ Características físicas } \\
\hline & \multicolumn{4}{|c|}{ Textura } & & \multicolumn{4}{|c|}{ Conteúdo de água no solo } \\
\hline & Areia & \multicolumn{2}{|c|}{ Silte } & Argila & & $-0,01 \mathrm{MPa}$ & \multicolumn{2}{|c|}{$-0,033 \mathrm{MPa}$} & $-1,5 \mathrm{MPa}$ \\
\hline & \multicolumn{5}{|c|}{ 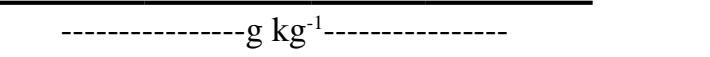 } & \multicolumn{4}{|c|}{ 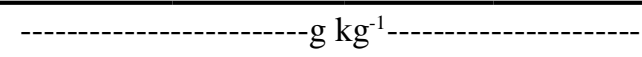 } \\
\hline \multirow[t]{2}{*}{ Alagoinha } & 452,0 & & & 361,0 & & 270,0 & & & 108,0 \\
\hline & \multicolumn{9}{|c|}{ Textura - Argilo Arenosa } \\
\hline \multirow[t]{2}{*}{ S. J. do Cariri } & 393,0 & \multicolumn{2}{|c|}{240,0} & 367,0 & & 257,0 & \multicolumn{2}{|c|}{191,0} & 127,0 \\
\hline & \multicolumn{9}{|c|}{ Textura - Franco Argilosa } \\
\hline \multirow[t]{3}{*}{ Locais } & \multicolumn{9}{|c|}{ Características químicas } \\
\hline & $\mathrm{pH}$ & $\mathrm{P}$ & $\mathrm{K}^{+}$ & $\mathrm{Na}$ & $\mathrm{H}^{+} \mathrm{Al}^{+3}$ & $\mathrm{Al}^{+3}$ & $\mathrm{Ca}^{+2}$ & $\mathrm{Mg}^{+2}$ & M.O \\
\hline & $\mathrm{H}_{2} \mathrm{O}$ & -----mg & $n^{-3}-----$ & -------- & ---------- & $-\mathrm{cmol}_{\mathrm{c}} \mathrm{dm}$ & $----\cdot$ & ------- & $\mathrm{g} \mathrm{dm}^{-3}$ \\
\hline Alagoinha & 6,10 & 2,00 & 65,00 & 0,21 & 2,64 & traços & 7,00 & 2,70 & 23,05 \\
\hline S. J. do Cariri & 6,30 & 2,00 & 85,00 & 0,52 & 1,15 & traços & 7,10 & 6,20 & 6,20 \\
\hline
\end{tabular}

120 dias após a emergência das plântulas, períodos correspondentes a 30 dias antes de cada corte.

Dessa forma, foram fornecidas dosagens de $\mathrm{N}, \mathrm{Pe}$ $\mathrm{K}$ entre as plantas colhidas aos 60; 90; 120 e 150 dias. As primeiras 96 plantas que foram eliminadas aos 60 dias receberam 0,0466 $\mathrm{g}$ de $\mathrm{N} ; 0,224 \mathrm{~g}$ de $\mathrm{P}_{2} \mathrm{O}_{5} ; 0,054 \mathrm{~g}$ de $\mathrm{K}_{2} \mathrm{O}$ nos tratamentos com $100 \%$ de água disponível em cada solo e 0,$037 ; 0,028 ; 0,019 \mathrm{~g}$ de $\mathrm{N}, 1,018 ; 0,013$; $0,089 \mathrm{~g}$ de $\mathrm{P}_{2} \mathrm{O}_{5}$ e 0,$004 ; 0,003 ; 0,002 \mathrm{~g}$ de $\mathrm{K}_{2} \mathrm{O}$ nos tratamentos relativos a 80,60 e $40 \%$ da água disponível de cada solo. As plantas colhidas aos 90, 120 e 150 dias receberam duas, três e quatro vezes os valores de cada nutriente em relação à primeira aplicação, ocorrida aos 60 dias após a semeadura.

Os dados foram submetidos à análise estatística utilizando o software Assistat (SILVA; AZEVEDO, 2002). As variáveis cujo teste $F$ detectou significância estatística foram submetidas à análise de regressão polinomial, testando-se os modelos linear, quadrático e cúbico. Neste caso, selecionou-se, para expressar os resultados, o modelo que apresentou maior coeficiente de determinação para os valores obtidos e que melhor expressou biologicamente o comportamento dos tratamentos avaliados. Vale ressaltar que a análise de variância para as variáveis proteína bruta da parte aérea e umidade do solo, foi realizada em separado, com solos e níveis de água como fatores de estudo.

\section{RESULTADOS E DISCUSSÃO}

Por meio dos quadrados médios dos tratamentos pode-se observar que houve efeito significativo de solos, da água e do corte dado às plantas de jureminha em todas as variáveis estudadas. Para os tratamentos com dados quantitativos, nas variáveis cujo teste $\mathrm{F}$ foi significativo efetuou-se a análise de regressão por polinômios ortogonais, testando os modelos linear, quadrático e cúbica, selecionando-se, para expressar os resultados, o modelo que apresentou maior coeficiente de determinação (Tabela 3).

No solo de Alagoinha, PB, as plantas cresceram linearmente em altura ao nível de $0,2614 \mathrm{~cm}$ por incremento unitário da água disponível atingindo valor máximo de 69,49 cm no solo com $100 \%$ de água disponível. No Vertissolo, as plantas cresceram até atingir $85,89 \mathrm{~cm}$ no solo com a disponibilidade hídrica máxima estimada de $78 \%$ (Figura 1A). O diâmetro do caule, em ambos os solos cresceu linearmente aos níveis de $0,1251 \mathrm{~mm}$ e $0,0872 \mathrm{~mm}$ por aumento unitário da disponibilidade hídrica com superioridade para o Vertissolo (Figura 1B). Tais resultados podem refletir as boas condições do sistema radicular das plantas cultivadas sob esse solo, que segundo Araújo et al. (2000) essa variável expressa mais confiantemente as boas condições do sistema radicular que o crescimento em altura.

A produção de matéria seca pela parte aérea das plantas cresceu com o aumento da disponibilidade hídrica nos dois solos, mas com superioridade no Vertissolo sobre o Nitossolo (Figura 1C). No solo de Alagoinha (Nitossolo) os valores aumentaram em 0,0646 g para cada aumento unitário de água disponível. No solo de São João do Cariri (Vertissolo) a produção de biomassa aumentou até o valor máximo estimado de água disponível de $87 \%$ produzindo $7,87 \mathrm{~g} \mathrm{planta}^{-1}$. 
Tabela 3 - Resumo das análises das variâncias para os dados de altura de planta (ALP), diâmetro caulinar (DIC), número de folhas (NFL), número de folíolos (NFO), matéria seca da parte aérea (MSP), matéria seca das raízes (MSR), proteína bruta (PRB) e umidade do solo (UMS) para o cultivo da jureminha. Areia-PB, 2006

\begin{tabular}{|c|c|c|c|c|c|c|c|c|c|c|}
\hline \multirow{2}{*}{ FV } & \multirow{2}{*}{ GL } & \multicolumn{9}{|c|}{ Quadrados Médios } \\
\hline & & ALP & DIC & NFL & NFO & MSP & MSR & GL & PRB & UMS \\
\hline Solos (S) & 1 & $9617,80 * *$ & $1,61 * *$ & $52,79 * *$ & $1619,75 * *$ & $77,83^{* * *}$ & $7,62 * *$ & 1 & $15,99 * *$ & $929,89 *$ \\
\hline Água (A) & 3 & $679,46^{* *}$ & $1,80 * *$ & $5,47^{*}$ & $2520,59 * *$ & $47,50 * *$ & $1,10 * *$ & 3 & $2,30^{*}$ & $8572,60 * *$ \\
\hline Corte (C) & 3 & $5622,95 * *$ & $39,20^{* *}$ & $106,79^{* *}$ & $40384,14 * *$ & $248,87 * *$ & $11,29^{* *}$ & - & - & - \\
\hline $\mathrm{S} \times \mathrm{A}$ & 3 & $180,04 * *$ & $0,06^{\mathrm{ns}}$ & $3,00^{\text {ns }}$ & $184,64^{\mathrm{ns}}$ & $4,21 * *$ & $0,02^{\mathrm{ns}}$ & 3 & $0,00004^{\mathrm{ns}}$ & $202,52^{\mathrm{ns}}$ \\
\hline $\mathrm{S} \times \mathrm{C}$ & 3 & $103,20^{\mathrm{ns}}$ & $0,10^{\mathrm{ns}}$ & $0,72^{\mathrm{ns}}$ & $160,23^{\text {ns }}$ & $5,86^{* *}$ & $0,31 * *$ & - & - & - \\
\hline $\mathrm{A} \times \mathrm{C}$ & 9 & $0,38^{\mathrm{ns}}$ & $0,02^{\mathrm{ns}}$ & $0,03^{\text {ns }}$ & $197,28^{\mathrm{ns}}$ & 0,01 & $0,001^{\text {ns }}$ & - & - & - \\
\hline $\mathrm{S} \times \mathrm{A} \times \mathrm{C}$ & 9 & $0,33^{\mathrm{ns}}$ & $0,02^{\mathrm{ns}}$ & $0,03^{\text {ns }}$ & $213,62^{\mathrm{ns}}$ & 0,01 & $0,001^{\text {ns }}$ & - & - & - \\
\hline Erro & 62 & 38,40 & 0,04 & 1,89 & 92,10 & 0,41 & 0,013 & 16 & 0,84 & 131,97 \\
\hline $\mathrm{CV}(\%)$ & - & 8,64 & 8,29 & 9,37 & 8,79 & 10,19 & 8,21 & - & 8,91 & 9,22 \\
\hline
\end{tabular}

$\left({ }^{* *}\right),\left({ }^{*}\right),\left({ }^{\text {ns }}\right)$ significativos a $1 \%, 5 \%$ e não significativo respectivamente, pelo teste $\mathrm{F}$

Figura 1 - Altura de planta (A), diâmetro caulinar (B), matérias secas da parte aérea (C) e raízes (D), em função dos níveis de água disponível nos solos (Nitossolo-Alagoinha-PB e Vertissolo-São João do Cariri-PB)
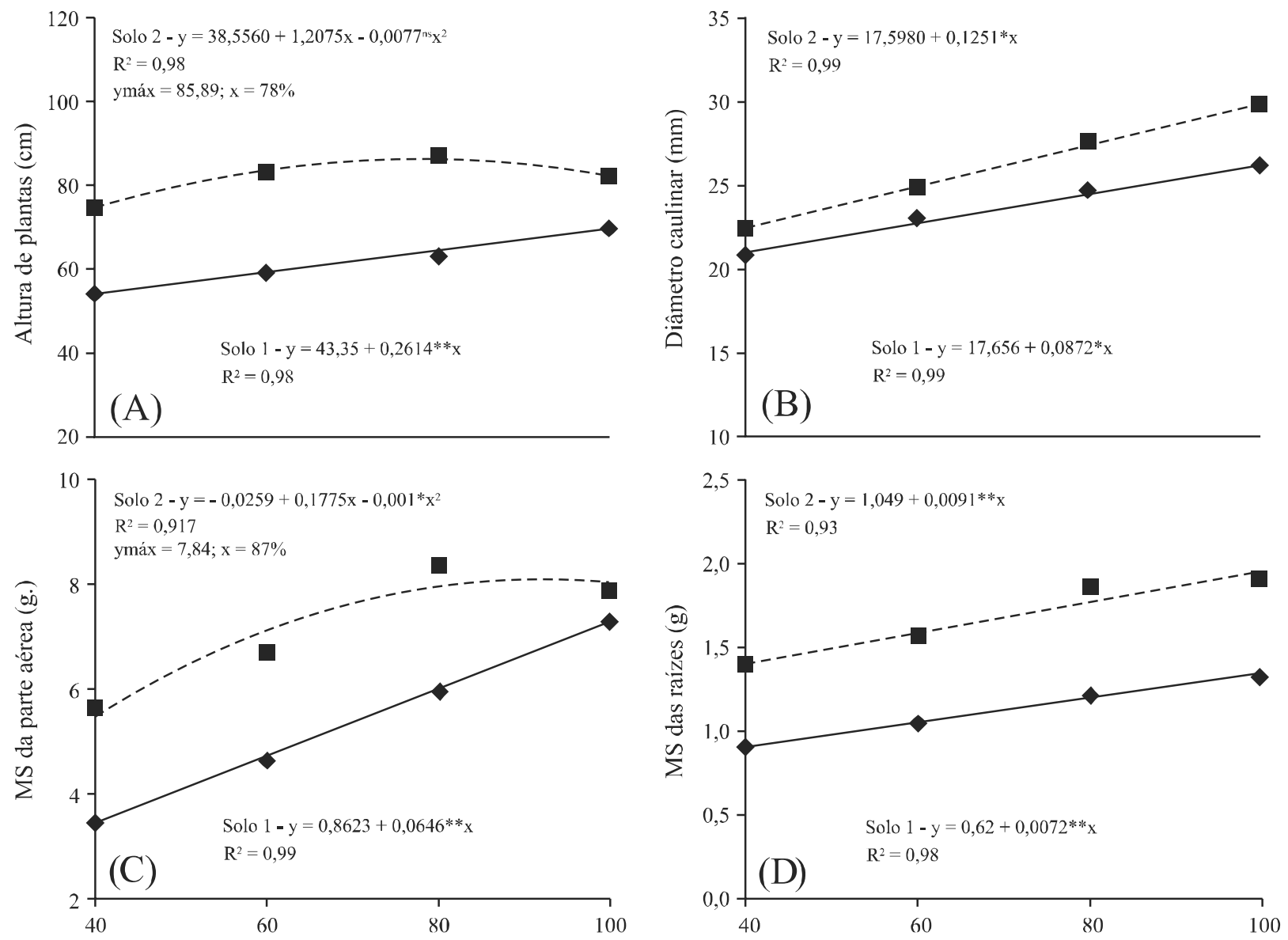

Água disponível (\%)

$\left(^{* *}\right),\left({ }^{*}\right),\left({ }^{\text {ns }}\right)$ significativos a $1 \%, 5 \%$ e não significativo, respectivamente, pelo teste $\mathrm{t}$ 
Independentemente do solo, a biomassa seca das raízes aumentou linearmente em função dos teores de água disponível às plantas (Figura 1D). Como nas demais variáveis da Figura 1, se constatou superioridade dos valores nas plantas cultivadas no Vertissolo comparadas àquelas no Nitossolo. Essa superioridade pode ser devido aos menores teores de areia e maiores de cálcio, magnésio e potássio deste último solo, resultando em maior crescimento vegetativo e uma maior produção de biomassa da parte aérea e radicular da Jureminha. Ao considerar que os valores mais baixos referem-se aos menores teores de água disponível, a maioria das plantas sofreu o efeito depressivo da água no solo, isto é, as produções mais baixas foram obtidas nos tratamentos com menores teores de água (CARLESSO; SANTOS, 1999; GUEDES et al., 1996).
Na Figura 2 são apresentados os resultados dos números de folhas e de folíolos, de proteína bruta e umidade do solo, respectivamente, nos diferentes teores de água disponível. Pelos resultados, observa-se que os dados relativos ao número de folhas das plantas cultivadas no Vertissolo, atingiram o maior valor com 16,02 folhas por planta no solo com teor de água máximo estimado de $74 \%$ de água disponível. No Nitossolo a emissão do número de folhas aumentou linearmente ao nível de 0,299 folhas por cada aumento unitário da água disponível no solo (Figura 2A). Com relação ao número de folíolos, verificouse um ajuste linear dos dados nos dois solos utilizados com os maiores resultados atribuídos ao Nitossolo de São João do Cariri com incrementos de 10,05 e 5,79 folíolos para os dois solos estudados, respectivamente, por unidade de grama de água disponível por quilograma de solo (Figura 2B).

Figura 2 - Número de folhas (A) e de folíolos (B), proteína bruta (C) e umidade do solo (D) em função dos níveis de água disponível nos solos (Nitossolo-Alagoinha-PB e Vertissolo-São João do Cariri-PB)
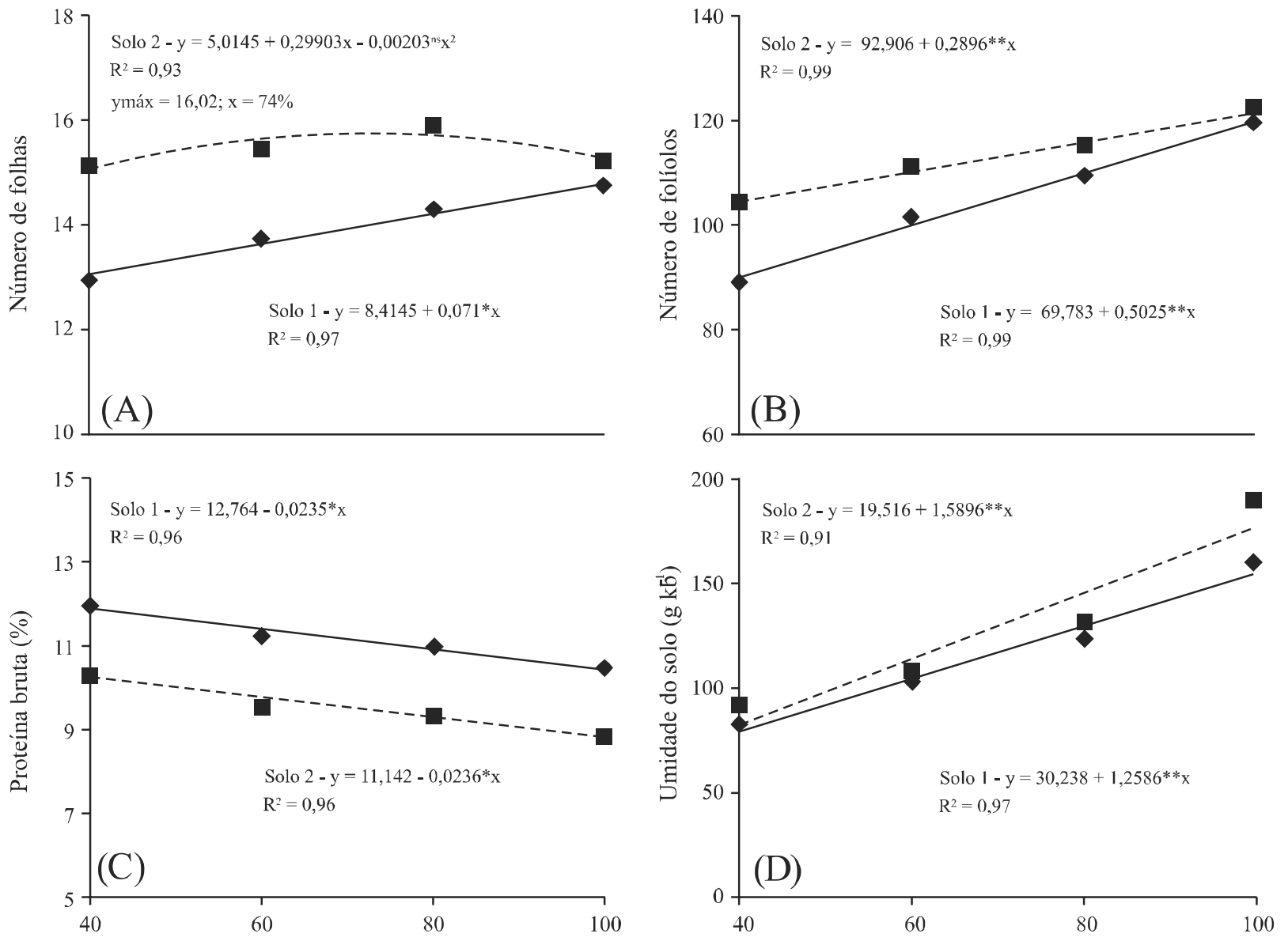

Água disponível (\%)

$\left({ }^{* *}\right),\left({ }^{*}\right),\left({ }^{\mathrm{ns}}\right)$ significativos a $1 \%, 5 \%$ e não significativo, respectivamente, pelo teste $\mathrm{t}$ 
Os resultados evidenciam a importância do Vertissolo em armazenar mais água e disponibilizar às plantas em relação ao Nitossolo, uma vez que os valores, exceto do teor de proteína bruta, foram superiores aos dos tratamentos do solo de Alagoinha (Nitossolo). Essa superioridade do Vertissolo é devida, possivelmente, ao solo de Alagoinha (Nitossolo) ser mais arenoso e apresentar menores teores de cálcio, magnésio e potássio. Esse comportamento foi semelhante ao apresentado por Diniz Neto et al. (2009) que ao trabalharem com Ricinus communis L., outra espécie tolerante à deficiência hídrica em dois solos do Estado do Ceará, constataram que o solo que armazenou mais água, promoveu os melhores resultados em relação ao crescimento vegetativo das plantas estudadas.

O aumento da disponibilidade de água, ao contrário das demais variáveis, inibiu os teores de proteína bruta na matéria seca da parte aérea das plantas em ambos os solos, mas com maior intensidade no Vertissolo (Figura 2C). O decréscimo dos teores de proteína bruta na biomassa foliar pode ser devido à maior absorção de água pelas plantas nos tratamentos com maior disponibilidade hídrica, resultando em maiores teores de cinza na matéria seca em detrimento da produção de proteína bruta. Essa tendência foi observada também por Costa et al. (1997) e Aragão (1989), onde o aumento de cinza das folhas das plantas resultou no declínio dos teores de proteína bruta em Jureminha.

O teor de umidade nos dois solos cresceu linearmente com o aumento da disponibilidade de água no solo, com superioridade para o Vertissolo de São João do Cariri (Figura 2D). Tal fato deve-se, em maior parte, ao menor teor de areia $\left(393 \mathrm{~g} \mathrm{~kg}^{-1}\right)$ e maior de silte mais argila (607 $\left.\mathrm{g} \mathrm{kg}^{-1}\right)$, em relação ao Nitossolo de Alagoinha com $452 \mathrm{~g} \mathrm{~kg}^{-1}$ de areia e $548 \mathrm{~g} \mathrm{~kg}^{-1}$ de silte mais argila. Nesse sentido, verifica-se que os solos menos arenosos, isto é, de textura mais fina (silte + argila) exercem maior capacidade de armazenamento de água (CARLESSO; SANTOS, 1999) comparado aos que possuem textura mais arenosa implicando em irrigações mais frequentes para o adequado crescimento das plantas (GARCIA; BEZERRA; FREITAS, 2007).

Os dados referentes ao crescimento em altura de planta e diâmetro caulinar, matéria seca da parte aérea e de raízes, números de folhas e de folíolos aumentaram com a idade das plantas em ambos os solos estudados, mas com superioridade nas plantas cultivadas no Vertissolo (Figura 3). As mesmas tendências, exceto proteína bruta, que foram registradas também para as respectivas variáveis, em função dos teores de água disponível nos solos (Figura 1 e 2), foram constatadas também em função da idade de corte das plantas. Pelos resultados, observou-se sempre os maiores valores para o Vertissolo em função da sua maior proporção de argila promovendo maior teor de água disponível e maiores conteúdos de cálcio, magnésio e potássio às plantas, proporcionando melhores rendimentos. Essa afirmativa parece óbvia, porém, para o suporte alimentar dos rebanhos torna-se importante avaliar a capacidade de produção sistemática da forragem, tanto em produção de massa verde como na qualidade do material obtido, conforme alerta Guim (1999).

A biomassa seca da parte aérea e das raízes aumentou expressivamente com a idade das plantas nas distintas idades de corte entre os solos, com os maiores valores no solo de São João do Cariri (Vertissolo) em relação ao solo de Alagoinha (Nitossolo) como indicado nas Figuras 3C e 3D. Observou-se também, que as plantas tiveram um aumento expressivo na sua biomassa a partir do nonagésimo dia de cultivo e esse comportamento foi semelhante entre os dados da biomassa seca da parte aérea e das raízes, devido possivelmente, à maior capacidade fotossintética das plantas pelo maior número de folhas e folíolos produzidos a partir dessa idade. Nesse sentido, pode ter ocorrido aumento na taxa fotossintética, como resultado da interação das variações dos fatores ambientais, como a disponibilidade de água, e cronológico, como a idade das folhas, permitindo avaliar a eficiência no uso da água, sendo essa interação importante no esclarecimento dos efeitos presentes nos vegetais quando da produção de biomassa (LARCHER, 2000; PINZÓN-TORRES; SCHIAVINATO, 2008).

Os números de folhas e de folíolos foram baixos em ambos os solos até os 90 dias de cultivo, aumentando a partir dessa idade, mas sempre com os menores resultados obtidos no Nitossolo de Alagoinha em relação ao Vertissolo de São João do Cariri. O reduzido número de folhas e de folíolos até os primeiros 90 dias após a emergência pode estar relacionado com a fenologia da espécie ou como forma de adaptação às condições imposta pelo meio (Figura 3E e 3F). Para Pinzón-Torres e Schiavinato (2008), qualquer que seja o tipo de adaptação, fisiológica ou morfológica, poderá influenciar a planta como um todo e, desse modo, o incremento da biomassa das raízes ou da parte aérea, avaliados como crescimento, ocorre em função de um componente morfológico principal, a área foliar, que se modifica conforme a planta avança nos estádios fenológicos, fato que pode estar relacionado com o comportamento da jureminha, nos primeiros 90 dias após a emergência. 
Figura 3 - Altura de planta (A), diâmetro caulinar (B), matérias secas da parte aérea (C) e de raízes (D), números de folhas (E) e de folíolos (F) em função do corte das plantas em Nitossolo e Vertissolo, respectivamente, dos municípios paraibanos de Alagoinha e São João do Cariri
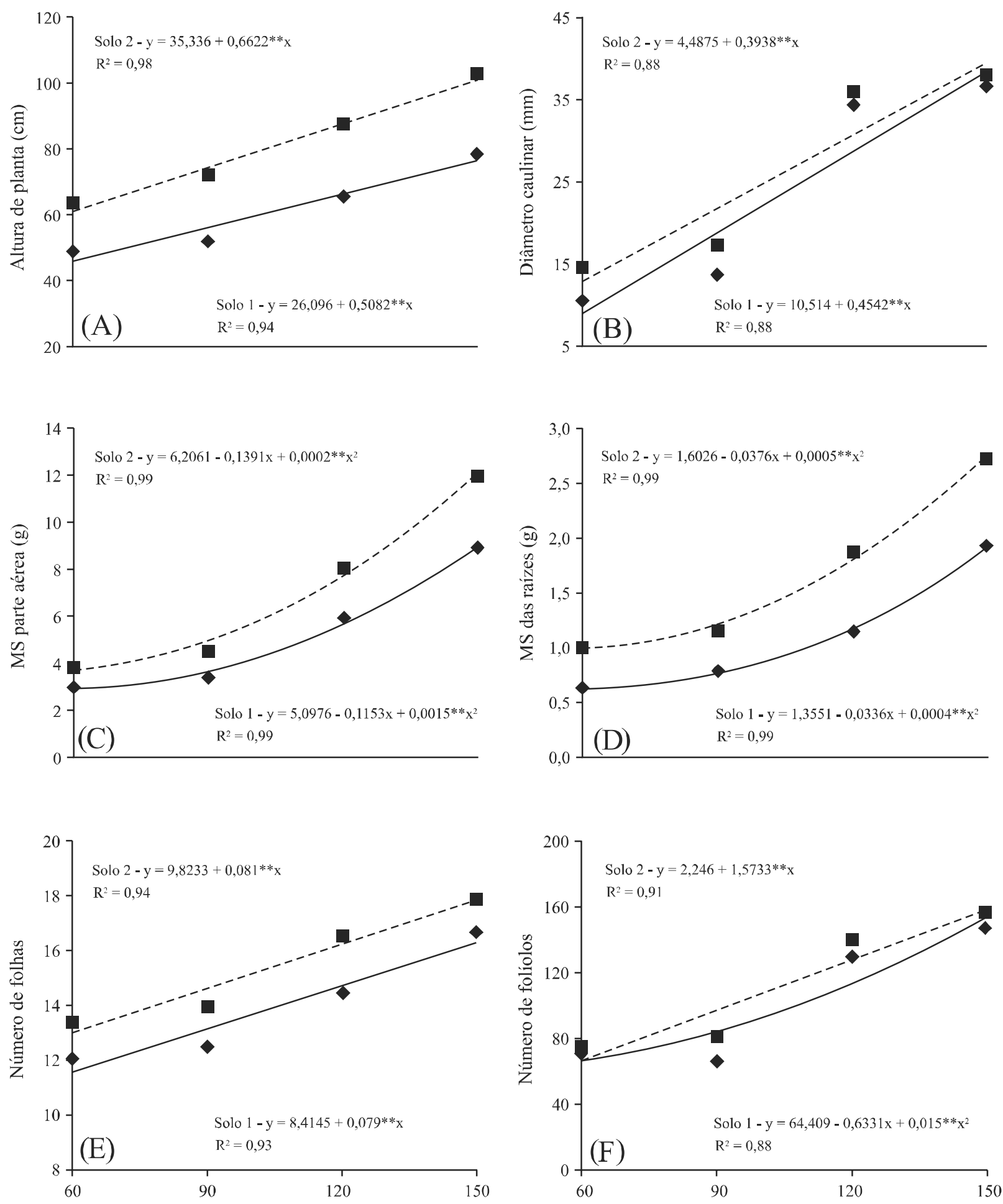

Idade de corte (dias)

$\left({ }^{* *}\right),\left({ }^{*}\right),\left({ }^{n s}\right)$ significativos a $1 \%, 5 \%$ e não significativo respectivamente, pelo teste $\mathrm{t}$ 


\section{CONCLUSÃO}

O aumento da água disponível estimula o crescimento e a produção de biomassa das plantas de Jureminha com destaque para o Vertissolo, mas reduz o teor de proteína bruta, com maior decréscimo para esse solo que apresentou maior teor de água disponível que o Nitossolo.

\section{REFERÊNCIAS}

ALCÂNTARA, P. B.; BUFARAH, G. Plantas forrageiras: gramíneas e leguminosas. São Paulo: Nobel, 1999. 150 p.

ARAGÃO, W. M. Estudo da variabilidade de caracteres morfológicos e agronômicos em populações de Desmanthus virgatus (L.) Wildd. (Leguminosae - Mimosoideae) nativas de Sergipe. 1989. 199 f. Tese (Doutorado em Agronomia) Escola Superior de Agricultura Luiz de Queiroz, Piracicaba, 1989.

ARAÚJO, D. C. de et al. Efeito do volume de água e da cobertura morta sobre o crescimento inicial do maracujazeiro amarelo. Revista Brasileira de Engenharia Agrícola e Ambiental, v. 4, n. 1, p. 121-124, 2000.

ASSUNÇÃO, S. L.; FELFILI, J. M. Fotossociologia de um fragmento de cerrado sensu stricto na APA do Paraná, DF. Brasil. Acta Botânica Brasílica, v. 18, n. 4, p. 903-909, 2004.

BOUYOUCOS, G. J. A. A recalibration of the hidrometer method for making analysis of soil. Agronomy Journal, v. 43, n. 9 , p. 434-437, 1951.

CARLESSO, R.; SANTOS, R. F. Disponibilidade de água às plantas de milho em solos de diferentes texturas. Revista Brasileira de Ciência do Solo, v. 23, p. 17-25, 1999.

COSTA, F. G. P. et al. Avaliação do feno de maniçoba (Manihot pseudoglaziovii Paz \& Hoffman) na alimentação de aves caipiras. Revista Caatinga, v. 20, n. 3, p. 42-48, 2007.

COSTA, M. V. A. et al. Análise da composição químicobromatológica de seis espécies nativas das microrregiões do Cariri e Curimataú. In: ENCONTRO DE INICIAÇÃO CIENTÍFICA DA UFPB, 5., 1997, João Pessoa. Anais... João Pessoa-PB, 1997. p. 102. v. 23.

DANTAS NETO, J. et al. Influência da precipitação e idade da planta na produção e composição química do capim-buffel. Pesquisa Agropecuária Brasileira, v. 35, n. 9, p. 1867-1874, 2000.

DAY, P. R. Particle Fractionation and particle size analysis. In: BLACK, C. A. (Ed.) Methods of soil analysis. Madison: Amrican Society of Agronomy, 1965. p. 545-567.

DINIZ NETO, M. A. et al. Adubação NPK e épocas de plantio para mamoneira. I - Componentes da produção e produtividade. Revista Ciência Agronômica, v. 40, n. 4, p. 578-587, 2009.
EMPRESA BRASILEIRA DE PESQUISA AGROPECUÁRIA. Centro Nacional de Pesquisa de Solo. Manual de métodos de análise de solo. 2. ed. rev. atual. Rio de Janeiro, 1997. 212 p.

EMPRESA BRASILEIRA DE PESQUISA AGROPECUÁRIA. Centro Nacional de Pesquisa de Solo. Sistema de classificação de solos. Brasília: Embrapa Produção de Informações; Rio de Janeiro: Embrapa Solos, 2006. 306 p.

FIGUEIREDO, M. V.; PIMENTA FILHO, E. C.; GUIM, A. Avaliaçãoquímico-bromatológicadofenoda Desmanthusvirgatus (jureminha) em diferentes tempos de armazenamento. In: ENCONTRO DE INICIAÇÃO CIENTÍFICA DA UFPB, 7., 1999, João Pessoa - PB. Anais... João Pessoa, 1999. p. 131.

FIGUEIREDO, M. V. et al. Estudo descritivo de Desmanthus virgatus: uma revisão. In: CONGRESSO NORDESTINO DE PRODUÇÃO ANIMAL, 2., 2000, Teresina-PI. Anais... Teresina: SNPA, 2000. p. 341-344.

FONTENELE, A. C. F.; ARAGÃO, W. M.; RANGEL, J. H. de A. Biometria de furtos e sementes de Desmanthus virgatus (L) Willd nativas de Sergipe. Revista Brasileira de Biociências, v. 5, p. 252-254, 2007. Suplemento 1.

GARCIA, F. C. de H.; BEZERRA, F. M. L.; FREITAS, C. A. S. de. Níveis de irrigação no comportamento produtivo do mamoeiro Formosa na Chapada do Apodi, CE. Revista Ciência Agronômica, v. 38, n. 2, p. 136-141, 2007.

GUEDES, A. de M. et al. Microflora de sementes de jureminha - incidência e patogenicidade. Revista Agropecuária Técnica, v. 26, n. 1 , p. $68-70,2005$.

GUEDES, I. M. R. et al. Estresse hídrico, salino e de compactação: efeito sobre o estado hídrico e a acumulação de matéria seca em girassol. In: ENCONTRO DE INICIAÇÃO CIENTÍFICA DA UFPB, 4., 1996, João Pessoa. Anais... João Pessoa-PB: UFPB, 1996. 385 p. v. 3. Resumos.

GUIM, A. Desenvolvimento de sistemas de exploração de forrageiras nativas no semiárido paraibano com padrão de alto-sustentabilidade. Areia-PB: CCA/UFPB, 1999.

LARCHER, W. Ecofisiologia vegetal. São Carlos: Rima, 2000. $531 \mathrm{p}$.

LIMA, G. F. da C.; ARAÚJO, G. G. L. de; MACIEL, F. C. Produção e conservação de forragens para sustentabilidade dos rebanhos caprinos e ovinos na base da agricultura familiar. Tecnologia \& Ciência Agropecuária, v. 3, n. 4, p. 43-53. 2009.

LIMA, J. L. S. Plantasforrageiras das caatingas: uso e potencialidades. Petrolina: EMBRAPA-CPATSA/PNE/RBKEM, 1996. 43 p.

PINZÓN-TORRES, J. A.; SCHIAVINATO, M. A. Crescimento, eficiência fotossintética e eficiência do uso da água em quatro espécies de leguminosas arbóreas tropicais. Hoehnea, v. 35, n. 3, p. 395-404, 2008.

RICHARDS, L. A. Physical contition of water in soil. In: BLACK, C. A. Methods of soil analysis. Madison: American Society of Agronomy, 1965. p. 128-152. (Agronomy, 9). 
SILVA, D. J. Análise de alimento (Métodos químicos e biológicos). Viçosa-MG: UFV, 1990. 116 p.

SILVA, F. de A. S.; AZEVEDO, C. A. V. de. Versão do programa computacional Assistat para o sistema operacional windows. Revista Brasileira de Produtos Agroindustriais, v. 4, n. 1, p. 71-78, 2002.
SILVA, M. M. C. et al. Avaliação do padrão de fermentação de silagens elaboradas com espécies forrageiras do estrato herbáceo da caatinga nordestina. Revista Brasileira de Zootecnia, v. 33, n. 1, p. 87-96, 2004.

TEDESCO, M. J.; VOLK WEISS, S.; BOHNEN, H. Análises de solo, plantas e outros materiais. Porto Alegre: UFRGS, 1985. 188 p. 